\title{
A System Framework For Managing Learner Autonomy
}

Alexander Vengerov, Ramapo College of NJ

Gary Kettlitz, Ramapo College of NJ

Stephen Klein, Ramapo College of NJ

\begin{abstract}
The need to connect information systems studies with other concentrations in business school curricula requires the development of integral courses comprised of several knowledge domains. Students with different prior knowledge, skills and learning focus (e.g., business development, technology management, or programming) should be able to enroll in the same course. The resulting difficulties of such personalized classroom management techniques could be largely overcome through special learning designs and proper technological architecture. Presented results could be generalized for other complex non-linear course organizations.
\end{abstract}

\section{INTRODUCTION}

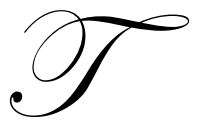

he growing impact of Information and Communication Technologies (ICT) on all areas of human activities requires the development of courses where the learning of computing and information systems is integrated with other majors. But the recommendations of ACM [1] for such ICT proliferation, when courses are "bent to fit user needs" have problems when used in a non-trivial course organization. This becomes especially noticeable for courses requiring rather advanced knowledge in all areas of material integration. Specifically, there is a growing need for integral courses connecting computing and technology with business contexts. This is evident in the attempts of such computing technologies as utility and grid computing to support customer value by direct connection with business processes and broad use of e-business methods [2, 3].

Another problem of teaching computing technologies is in their continuously changing and complex nature [4] requiring students to study problems in a broader and more dynamic context. The differences in pre-existing knowledge and skills, coming from various learning domains, as well as differences in student learning goals require highly personalized course design. One design-fits-all cannot satisfy sponsoring majors and also suppresses student's interest and learning effectiveness. The relationship between the growing power of autonomic selforganization and the cost of its proper support has to be analyzed in the context of various learning designs. Such courses as "E-Commerce" and "Introduction to IS" are examples of course offerings designed to support a broader perspective for the CS/IS students, while enriching, their understanding of the role of technology and computing in connection with other areas of study.

This paper analyzes the results of a five-year study of teaching an eCommerce course in search of the best way to satisfy the above-mentioned concerns. The main contribution of this paper is in the analysis of the specific case of Multitrack Multistage (MTMS) course organization [5] in its methods of managing and guiding autonomic learner's activities. The analysis of MTMS leads to the conclusion that the increased use of learners' autonomy in various areas of course organization is important, but has to be properly guided in order to guarantee the satisfaction of learning objectives. The seeming contradiction between autonomy and its guidance can be resolved within the MTMS framework.

The paper is divided into three sections. First, we describe the needs and difficulties associated with the use of highly autonomic student behaviors; second, we present the specific autonomy management mechanisms 
found to be useful in the experiments with MTMS course design; and third, we offer a description of the architecture supporting the beneficial use of mechanisms managing learners' autonomy.

\section{IMPORTANCE AND PROBLEMS OF LEARNERS' AUTONOMY}

The need for, and importance of, developing learner autonomy have been widely discussed $[10,11,12, \&$ 13.]. Learner autonomy can be seen as an available variety of learner's choices affecting an individual's learning workflow, learning objectives and strategies, the nature of resource procurement, and other parameters of the learning process. Empowering students ability to use autonomic behaviors has to be balanced with some guiding mechanisms $[6,7,8]$, where autonomy and control are not in direct trade-off or competition, but rather represent different areas of the overall organizational adaptivity.

Autonomy cannot be directly controlled - it breaks and loses its holistic coherence and ability to recreate inner meaning. On the other hand, poorly executed autonomy is worse than centralized control, usually used in course organization. One of the solutions to this problem, allowing to keep the course meaningful and coinciding with the preset learning goals while allowing for some autonomic activities, is in the sufficient empowering of autonomy [10] to the level when it becomes capable of efficient self-organization.

An alternative method of dealing with learners' autonomy [10] might prove useful. It is based on the design and proper administration of the course management pressures and mechanisms, allowing for soft guidance of the behaviors of local autonomies in a constructive way, corresponding to instructional goals and utilities. The increasing power of local autonomy should be counterbalanced with increasing sensitivity and distribution of the guiding mechanisms. For example, control mechanisms determine general polices ("rules of the game"), while autonomy is dedicated to the search of optimal strategies for those games. The interaction of both levels has to ensure that the local use of orientation, resources, and creativity results in strategies aligned with the overall learning objectives of the course design [5]. The execution of course models requires dynamic evolution of both levels [9].

\section{AUTONOMY MANAGEMENT IN ORGANIZATIONS}

Planning learning goals and deriving the structure of the completely controlled course is similar to attempts at designing business processes supporting predetermined goals. A number of techniques and modeling languages allow for such processes design [21, 22, 23]. At the same time, there is a growing consensus that agent autonomy has to play an important role and should not be fit into hierarchical control constructs.

Some insights from business organizational mechanism development can be helpful in learning design, and specifically the problem of the degree of managing autonomy. The balance between autonomy and organizational/process control is not a matter of a mix, but of crafting mechanisms that allow the use of necessary benefits derived from these polar methods. For example, centralized management can be associated with such features as stability, predictability, support of the necessary generality of knowledge and organizational culture, general efficiency etc. Autonomy offers the benefits of flexibility, adaptive ability, specialization, diversity, local effectiveness, and so on.

The use of specific mechanisms (like information technology, proper business process networking) allows for the necessary mix from both structures -- like having high flexibility and efficiency [24]. On the other hand, organizational design should allow for dynamic switching between the regimes of higher stability and flexibility

when encountering more or less dynamic environmental or internal situation [25], [26]. The proper management of autonomy might allow supporting the capacity for marginal substitution of actors, tasks, and sub processes in different autonomic entities [26].

Modern ICT allows for the design of the "mixing mechanisms" in a form of networks of mutual connectivity and sensitivity. Organizational and technological networks are known to be flexible tools occupying the middle ground between control pyramids and unregulated market forces. Management of the inherent node autonomy in networks can be implemented with various levels of managerial pressure. The modern approach is in 
seeing management of such socio-technological networks more like gardening -- when the major benefits and features of centralization and autonomy are properly mixed allowing the network to use its means of dynamic selforganization.

For example, the proper degree of generalization of operations and introduced knowledge can support better communications, collaborative, and adaptive behaviors, while maintaining the necessary level of expertise and local adaptivity [27, 28, 29, 30]. Certain generalization of knowledge and skills of local agents can help organizations to effectively meet changing environmental situations [31].

There have been multiple attempts to analyze the measure and benefits of various proportions of centralization/decentralization [26, 27, 32, 33, 34]. Decentralization of information flows and knowledge distribution have to be followed by decentralization of decision making and control [35]. However, decentralization of resources combined with high levels of autonomic control may increase coordination costs, workload, and performance, which leads to the need for management tradeoffs [36].

The combination of supported autonomies with the necessary level of their management/gardening requires the development of carefully crafted methods and mechanisms. "The first major component of post-industrial strategy is to seek that combination of businesses, array of internal services, and the structure for organizing them that promotes synergies -- a whole that multiplies the value of its parts" [32 p. 7].

The management of autonomies in a variety of network processes leads to the distributed form of organization, which, in comparison to the decentralized forms, has the necessary degree of interactivity among the nodes and between local and global decision-making. The synergy of both worlds helps solve larger and more complex problems in less time than might be possible for high autonomy with insufficient interactivity management and support [37, 38]. No mix of "best practices" can replace the design and maintenance process, which considers multiple mutual influences and feedback among all mechanisms and methods used in balancing the centralized perspective of the whole and autonomy of the loci $[39,40,41]$.

\section{LESSONS OF AUTONOMY MANAGEMENT IN AN ECOMMERCE COURSE}

In order for the previously described "soft guiding force" to positively influence local autonomic dynamics, it has to be implemented as a clear social construct, institutionalized to the point of becoming an important influential factor in behavioral organization via common understanding and acceptance of the "rules of the game." At this point, it becomes an organizational mechanism [10] with structural and procedural arrangements known and accepted by all participants. Then it can, and should, be reinforced by ICT, thereby increasing its effectiveness and efficiency in order to form a system architectural framework. Conducted studies $[14,15,18]$ show the importance of such a combination of organizational mechanisms with distributed data application and administration for advanced knowledge creation.

The areas of freedom of choice in setting individualized learning environments and workflows have been described in previous publications [10]. Here, we present the organization and experience of setting the course management or, rather, guiding mechanisms that, while coevolving with the dynamics of the totality of individual learner's behaviors, provide the necessary guarantee of the proper development of the learning process.

The overall organization of such mechanisms for the e-Commerce course draws on positive experiences in several areas: modern approach to the design of model-driven architectures for general systems analysis and design in its incremental methodology, problem-solving organization in its formation of a series of steps converging at a solution [19], and a workflow-based learning approach contributing to the tight management of the workflow on each step [20] in its interaction with the evolving environment. As a result, the course has three internal tracks or concentrations (business, technology, and programming) with task collaboration among them and a series of incremental steps (roughly a week in duration) allowing a gradual movement from a more divergent form of the initial exploration of the material to the convergence on individual, group, and course learning goals in their mutual alignment. The second specific design effort was focused on method engineering, where every stage has its own 
system of instructional and pedagogical methods satisfying the goals of that stage. A more detailed account of mechanism composition and changes of their relative influence and importance at every stage can be found in [5]. Below is a brief description of the somewhat aggregated for this paper stages, goals, methods and technologies, used in the course.

The main mechanisms used in various mixes on stages of E-Commerce version of MTMS include:

- Individual and group competition -- based on a grading curve.

- Mechanisms of social enrichment/constraints (e.g. groups/team relationships under competitive pressures; individual activities visible to the whole class and available for later reviews).

- $\quad$ Project-based learning guiding partial actions and providing various types of feedback.

- Task-based learning as small focused efforts with timely feedbacks (automated and personalized). Note that this could be dangerous for integral multitrack courses since can lead to the loss of perspective and, therefore, has to be combined with activities developing macro vision of the whole field of the study.

- $\quad$ Adaptive grading allowing students to earn course points (based on the curve) in various ways, controlled by stage contracts.

- $\quad$ P2P Interactions shaping social standing, social approval along with other organizing social influences. This must be gently moderated, since might self-organize to meaningless or even disruptive forms.

- Direct administrative controlling interventions, used when "soft management methods" will take too long to work and the situation is critical. This requires a careful balance between "therapy" and "surgery" approaches.

- $\quad$ The use of various types of assisting feedbacks that do not have such drastic punishing/rewarding effects as test grading, but are very useful for learner's timely adaptation. One example can be seen in intra-group accounting (student grading) of individual results in order to re-distribute the overall weekly group score. The immediacy of the teacher's or system's comments can also be very useful.

- Just-in-Time (JIT) learning combined with Web-based and automated-support learning stimulate the individual explorations and deeper/broader excursions into the material within the chosen tracks.

- $\quad$ Presentation-based learning as a mechanism exerting additional pressure of the need in success and social approval during the final integration and necessary enhancement of project parts. If each individual grade somewhat depends on the group outcome, then it pulls together various intra-group interests.

- Mechanisms promoting individual responsibility for educational outcomes, the need to reflect on it, understand that they are in charge instead of blaming/trusting the teacher. This results in activation of individual interests, formulating goals, and (re)design of individual utility of learning efforts for various stages and the whole course.

Experimentation with MTMS showed the effectiveness of its design. It also demonstrated improvements (compared to the lecturing/testing style) in the depth, enthusiasm, and quality of weekly research activities. The effectiveness of autonomic behaviors was seen as an increased energy, flexibility, and satisfaction of self- and group-learning, where students had to consider multiple factors like interests of others, project quality, new ideas, and newly obtained knowledge, etc. Another important benefit can be seen in the increased ability for self-guided Just-In-Time (JIT) Web learning, supporting the freedom of choices of learning resources, depending on the current interests, needs, and abilities.

At the same time, the need for the aforementioned soft guidance/pressure on each stage of the course workflow is different for different students/groups, becoming at times significant. Such spikes in the use of the guiding power of the stage mechanisms were correlated with weak feedback impacts and their frequency. Delays in the instructor's grading and responses to the student's activities, especially if combined with possible inefficiency of group interactions due to the poor use of communication technologies and unnoticed deviations from the set policies of the group conduct, resulted in autonomic behaviors (or inactivity) requiring much stronger controlling interventions than normally would be necessary.

The expressed aspects of the effectiveness of the MTMS framework and the need in its efficient execution lead to the two alternative uses of the approach. One is in the low-tech implementation of MTMS, with social 
construction of the working mechanisms of autonomy management based on the instructor's personal interest and enthusiasm, needed for additional time resources compared to the usual lecturing and testing activities. Another way is in the adequacy of the technological support of the management mechanisms, allowing them to become distributed and autonomic without significant increase in course administration efforts [16]. Such technologysupported autonomy of management mechanisms based on distributed processing and decision support systems allows to match the growth in the necessary autonomic empowerment (and therefore variability) of the learners' behaviors without significant increase in teaching efforts.

\section{A FRAMEWORK FOR SYSTEM SUPPORT OF MANAGEMENT MECHANISMS}

The previously described methods used in course organization can be effectively supported by the proper ICT architecture and technologies. ICT-supported instructional methods have their parameters, procedures, connectivity, and position in the workflow. This effectively transforms them into a more formalized category of design patterns or mechanisms.

Course and learning management systems should allow for enhanced management of learner autonomy, while using the guiding pressures of the Management Mechanisms (MM), including:

- $\quad$ Feedback enhancement and accessible statistical memory supporting the effectiveness of pressure and adaptive behaviors.

- $\quad$ Easy and quick feedback delivery, using modern messaging, push and pull methods (like periodic popups of problems, attention grabbers/switches, and personal automated advisers for possible corrections and general help)

- Technologies providing support in the analysis/integration of event and feedback meaning control (using decision-support systems - DSS, OLAP tools, distributed artificial intelligence, etc.) as rich viewing of the current state, trends, threats, and opportunities

- Clear explanations of the stage contract structure. Here each week presents its own set of "games" with specific rules/policies and easily identifiable strategies of the "winning performance."

A framework is an architectural pattern that provides an extensible template for applications within a domain [17]. The top level of framework abstractions includes collaborations, use cases, and mechanisms integrated into a hierarchy of architectural and design patterns. The high-level architecture of MTMS framework, showing the use of the MM that ensures effectiveness of learner autonomy (LA), is presented below (fig. 1).

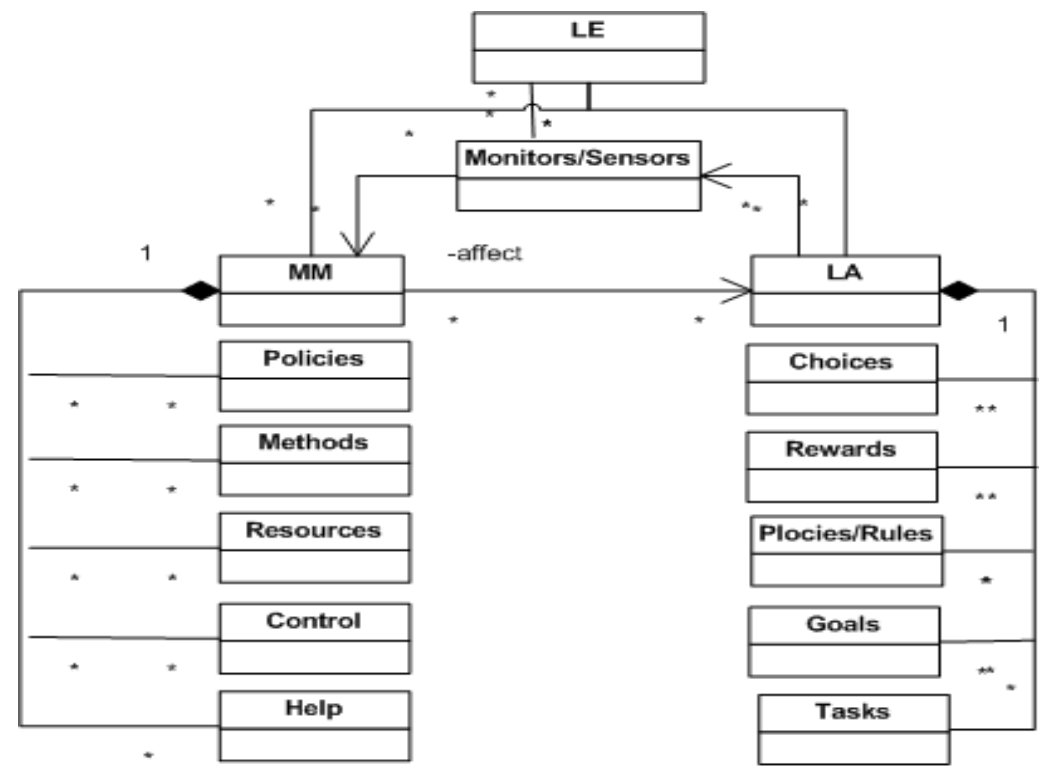

Fig. 1 Framework of system support for management mechanisms 
Every mechanism in a Mechanism Management (MM) block has a special system support of the Learning Environment (LE), including management and communication of its states, operations, resource composition, policies of activation and influence, etc. These mechanisms do not just use ICT to increase their force, but lend the effectiveness of their very existence to the quality and timelessness of sensors, feedback loops, interpretations, and interactions. In many cases they allow evolving wholes to lead their autonomic parts, while being sensitive to the successful developments in these parts [9]. For example, one of the ways a group influences its individual members can be based on group scheduling with resulting individual actions delivered to each member and integrated with all views of learner activities (like time management, scheduling support, etc.). Other means can include: groupdeveloped accounting tables, agreed glossaries, project structure, planned activities, popup invitations for chat, signals showing discussions waiting response, comments about work done, and other signals and interactions.

Both MM and LA subsystems are connected to the means representing and monitoring the rest of the LE, that include data and models of control-autonomy coevolving dynamics, as well as other forces and factors influencing the currently executed learning process. An important part of the architecture is a monitoring/sensing system typical for distributed organizations. It can receive messages from various actions as well as observing and collecting information on its own. In essence, it is a sensor network collecting information, interpreting and integrating data to the level of local and more global meaningful "events," and passing the resulting event signals to the subscribers, sensitive to them. For example, the information about assessments for different students and topics can be integrated into the picture of the learners "not getting" a certain concept or insufficient level of constructivist projects. This in turn can trigger the need of adaptive adjustment of the course flow and its aspects.

The Mechanism Management (MM) subsystem should include the following main parts: policies, guiding the degrees of freedom and keeping pressures on LA; methods, chosen for the particular way of exercising these pressures and restrictions; and resources chosen/recommended for the support of the applied methods. In addition, there should be means supporting less ICT-dependable and more traditional means of direct instructor's control pressure or help when other means cannot alleviate the problem.

The instructor-managed means and tools allow changing policies, methods, and resources that regulate group and individual choices via direct notification or indirect impact on various parameters (that will change the view of their LEs). For example, a policy might state that if an instructors' message appears in the research discussion, replying to it according to the specified in the message manner is mandatory and leads to additional point rewards for quality (or deductions for ignoring). Method here might be described as a guided discussion and additional resources might be specified as links in the same message. Such change might be a way an administrator exercises the guiding/mediating role over the discussion flow, when it deviates from the intended focus. An example of indirect influence of changes in MM can be seen in the change in available learner's choices at any decisionmaking point when the learner's DSS [10] offers solutions or an advice on the strategy of reward maximization and the proper use of resources.

The subsystems supporting LA for individuals, groups, and ad hoc communities have to be designed to ensure learner effectiveness in achieving their goals, but also to be sensitive to various changes in managing mechanisms that can automatically adjust some of the local parameters in direct or indirect fashion. In a way, MM determines the corridor of opportunities, while the LA means support the possibility of choosing the best strategy of moving along such corridor in a most efficient way. The LA subsystems should include such components as: available choices (of resources, actions, plans, etc.); possibility to assess the rewards connected with each choice; and clear explanations of policies and rules related to each choice/reward/situation triple. In addition, the system should assist in choosing/modifying strategies comprised of goals and tasks that the learners perceive as important in order to cope with their choices. It is important that all the LA components are automatically registering the changes (as events), in the managing mechanisms, supporting the integrity of the created learning situation on every stage. This ensures that the chosen actions and resources are aligned with the learners' tasks and goals. 


\section{CONCLUSION}

Based on the analysis of the case of the MTMS framework use in eCommerce course design, this paper shows the importance of the enhanced use of learner autonomy, supplemented by the carefully configured means of the course flow management. It also extends the concept of course design and management to more complex forms of a multilevel co-evolution of the local autonomy with means ensuring its effectiveness for the whole learning process. Such forms of adaptive control require the addition of enhanced ICT services and special subsystems to the LMS functionality. Further, the paper outlines the basic features of such course organization and the main aspects of LA/MM interaction based on enhanced systems support. The resulting methodology of converting instructional methods into socio-systemic mechanisms with the help of the proper social design, institutionalization, and technological support showed positive results in eCommerce course experiments and support the importance of the future research in this direction.

Properly enhanced ICT support is capable of making the MTMS-like designs viable, scalable, and effective, instead of being able to exist only due to the extensive time investment by instructors-enthusiasts only. The MTMS framework forms a sufficiently stable and well-working design, allowing it to be considered a solution (architectural pattern) to the posted problem. In our opinion, such domain-integrated courses as eCommerce can benefit from MTMS design in terms of learning quality, quantity, and instructor's efficiency.

\section{REFERENCES}

1. A. Vengerov, Distributed Autonomy Support In MTMS Course Framework, Proceedings of the Twelfths Annual Northeastern Conference of The Consortium for Computing in Small Colleges, 2007

2. A. Vengerov. Toward Integrated Pattern-Oriented and Case Base Design Framework in Complex Multiagent System Development for E-Business Environments. ASBBS International Conference, London, 2003

3. Adkins Sam, Workflow-Based E-Learning: Next-Generation Enterprise Learning Technology, 2003, http://www.learningcircuits.org/2003/aug2003/adkins.htm [November 2006]

4. Baker, W.E., The Network Organization in Theory and Practice, in Networks and Organizations, N. Nohria and R.G. Eccles, Editors. 1993, Harvard Business School Press: Boston, MA. p. 397-429.

5. Bandura, A., Self-efficacy: The exercise of control. New York: Freeman, 1997.

6. Brynjolfsson, E., A.A. Renshaw, and M. Van Alstyne, The Matrix of Change: Sloan Management Review, 1997.

7. Casati, F., Shan, M., and Georgakopoulos, D., E-Services - Guest editorial. The VLDB Journal. 10(1):1, 2001.

8. Drucker, P., The Coming of the New Organization. Harvard Business Review, 1988. January-February: p. 45-53.,

9. Gasser, L. and R.W. Hill, Coordinated Problem Solvers. Annual Review of Computer Science, 1990. 4: p. 203-253.,

10. Grady Booch, James Rumbaugh, Ivar Jacobson, The Unified Modeling Language User Guide. $2^{\text {nd }}$ edition. Addison-Wesley, 2005

11. Hannan, M.T. and J. Freeman, The Population Ecology of Organizations. American Journal of Sociology, 1977. 82(5): p. 929-962.

12. Hayek, F.A., The Use of Knowledge in Society. American Economic Review, 1945. 35(4): p. 3-17.

13. Higgins, Monica C., and Kathy E. Kram. Reconceptualizing Mentoring at Work: A Developmental Network Perspective. Academy of Management Review 26, no. 2: 264-288, April 2001

14. http://www.acm.org/education/curric vols/IT October_2005.pdf Computing Curricula. Information Technology Volume. ACM. Version: October 2005

15. Huber, George P., Managerial Decision Making. Glenview, IL: Scott, Foresman and Company, 1980

16. Kanter, R.M., The Future of Bureaucracy and Hierarchy in Organizational Theory: A Report from the Field1989, Harvard Business School: April,,

17. Kephart J. and Chess, D., The Vision of Autonomic Computing, IEEE Computer, Vol. 36, No. 1, p. 41-50, January 2003 
18. Kueng P., Kawalek P. Goal-Based Business Process Models: Creation and Evaluation. Business Process Management Journal, 1997, Vol. 3:1, pp.17-38..

19. Malone, T.W., J. Yates, and R.I. Benjamin, Electronic Markets and Electronic Hierarchies. Communications of the ACM, 1987. 30(6): p. 484-497.

20. Malone, T.W., Organizing Information Processing Systems: Parallels Between Human Organizations and Computer Systems, in Cognition, Computation, and Cooperation, W. Zachary, S. Robertson, and J. Black, Editors. 1989, Ablex Publishing: Norwood, NJ. p. 56-83.

21. Milgrom, P. and J. Roberts, Complementarities and Fit: Strategy, Structure, and Organizational Change in Manufacturing. Journal of Accounting and Economics, 1993. 19(2-3),

22. Morrison, E.W., Newcomer information seeking: Exploring types, modes, sources, and outcomes. Academy of Management Journal. 36, 557-589, 1993

23. Nambisan, S., Agarwal, R., and Tanniru, M., Organizational Mechanisms for Enhancing User Innovation in Information Technology, MIS Quarterly, 23(3), pp. 365-395, 1999

24. Niman, N.B., Modeling Coordination in Organizations and Markets. Management Science, 1992. 38(12): p. 1819-1826.

25. Nolan, R. and D. Croson, Creative Destruction. 1995, Boston: Harvard University Press. 259.].

26. Nurcan, S. and Rolland, C. A Multi-Method for Defining the Organizational Change Information and Software Technology Journal 45 (2003) 61-82.

27. P. J. DiMaggio and W. W. Powell, The iron cage revisited: Institutional isomorphism and collective rationality in organizational fields, Amer. Sociolog. Rev., vol. 48, pp. 147-160, Apr. 1983.

28. P. R. Lawrence and J. W. Lorsch, Organization and Environment. Boston: Harvard Grad. Sch. Bus. Admin., 1967.

29. Piore, M.J., Fragments of a Cognitive Theory of Technological Change and Organizational Structure, in Networks and Organizations, N. Nohria and R.G. Eccles, Editors. 1993, Harvard Business School Press: Boston, MA. p. 430-444.,

30. Popper, M. and Lipshitz, R., Organizational Learning Mechanisms: A structural and cultural approach to organizational learning, Journal of Applied Behavioral Science, 34(2), pp 161-179, 1998

31. Prahalad, C.K. \& Doz, I. L., The Multinational Mission: Balancing Local Demands and Global Vision, Free Press, New York, 1987

32. Radner, R., Hierarchy: The Economics of Managing. Journal of Economic Literature, 1992. XXX: p. 13821415.,

33. S. Klein, A. Vengerov, EQAL Approach to the Design of Learning Technology in Dynamic Information Contexts. Proceedings of the Fifth Annual Northeastern Conference of The Consortium for Computing in Small Colleges, 2000

34. Sabel, C., Moebius-Strip Organizations and Open Labor Markets: Some Consequences of the Reintegration of Conception and Execution in a Volatile Economy, in Social Theory for a Changing Society, P. Bairdieu and J.S. Coleman, Editors. 1991, Westview Press: Boulder, CO. p. 23-61.

35. Sah, R. and J. Stiglitz, The Architecture of Economic Systems: Hierarchies and Polyarchies. American Economic Review, 1986. 76(4): p. 716-727]

36. Serfaty, D. and D.L. Kleinman. Adaptation Processes in Team Decision Making and Coordination. in IEEE Symposium on Systems, Man, and Cybernetics. 1990.]

37. Shih-Wei Chou, Su-Ju Wang, Hsing-Pang Chen, Facilitating Knowledge Management with Information Management and Organizational Mechanisms. Proceedings of the 36th Annual Hawaii International Conference on System Sciences (HICSS'03). Volume 8. Page: 260.3, 2003

38. Simon, H., Administrative Behavior. 3rd. ed. 1976, New York: Free Press.

39. Tsalgatidou, A and Pilioura, T., An Overview of Standards and Related Technology in Web services. Distributed and Parallel Databases. 12(3), 2002

40. VanLamsweerde, A. Goal-Oriented Requirements Engineering: A Guided Tour Proc of the 5th IEEE Int. Symp. on Requirements Engineering, pp:249-262, 2001

41. Vengerov A., Klein S., An Approach to Multitrack Multistage Course Design, The International Journal of Learning, vol. 13, issue 3, 2006 